\title{
Serum ferritin contributes to racial or geographic disparities in metabolic syndrome in Taiwan
}

\author{
Jung-Su Chang ${ }^{1}$, Shive-Ming Lin ${ }^{2}$, Jane C-J Chao', Yi-Chun Chen ${ }^{1}$, Chi-Mei Wang ${ }^{1}$, \\ $\mathrm{Ni}-\mathrm{H}$ sin Chou ${ }^{1}$, Wen-Harn Pan ${ }^{3,4}$ and Chyi-Huey Bai ${ }^{2, *}$ \\ ${ }^{1}$ School of Nutrition and Health Sciences, Taipei Medical University, Taipei City, Taiwan, Republic of China: \\ ${ }^{2}$ Department of Public Health, College of Medicine, Taipei Medical University, 250 Wu-Hsing Street, Taipei City, \\ Taiwan 110, Republic of China: ${ }^{3}$ Institute of Biomedical Science, Academia Sinica, Nankang, Taipei, Taiwan, \\ Republic of China: ${ }^{4}$ Institute of Population Health Sciences, National Health Research Institutes, Zhunan, Miaoli \\ County, Taiwan, Republic of China
}

Submitted 19 September 2012: Final revision received 17 April 2013: Accepted 8 May 2013: First published online 18 July 2013

\begin{abstract}
Objectives: Asians and Pacific Islanders have higher circulating serum ferritin (SF) compared with Caucasians but the clinical significance of this is unclear. There is a higher prevalence of metabolic syndrome (MetS) in Taiwanese Indigenous than Han Chinese. Genetically, Indigenous are related to Austronesians and account for $2 \%$ of Taiwan's population. We tested the hypothesis that accumulation of Fe in the body contributes to the ethnic/racial disparities in MetS in Taiwan.

Design: A population-based, cross-sectional study.

Setting: National Nutrition and Health Survey in Taiwan and Penghu Island.

Subjects: A total of 2638 healthy adults aged $\geq 19$ years. Three ethnic groups were included.

Results: Han Chinese and Indigenous people had comparable levels of SF. Austronesia origin was independently associated with MetS (OR $=2 \cdot 61,95 \%$ CI $2 \cdot 02,3 \cdot 36$ ). After multiple adjustments, the odds for MetS (OR $=2 \cdot 49$, $95 \% \mathrm{CI}$ $1 \cdot 15,5 \cdot 28)$ was significantly higher among Indigenous people in the highest SF tertile compared with those in the lowest tertile. Hakka and Penghu Islanders yielded the lowest risks $(\mathrm{OR}=1 \cdot 08,95 \% \mathrm{CI} 0 \cdot 44,2 \cdot 65$ and $\mathrm{OR}=1 \cdot 21,95 \% \mathrm{CI}$ $0 \cdot 52,2 \cdot 78$, respectively). Indigenous people in the highest $\mathrm{SF}$ tertile had increased risk for abnormal levels of fasting glucose (OR $=2 \cdot 34,95 \%$ CI $1 \cdot 27$, $4 \cdot 29)$, TAG $(\mathrm{OR}=1 \cdot 94,95 \% \mathrm{CI} 1 \cdot 11,3 \cdot 39)$ and HDL-cholesterol $(\mathrm{OR}=2 \cdot 10,95 \%$ CI $1 \cdot 18,3 \cdot 73)$ than those in the lowest SF tertile.

Conclusions: Our results raise the possibility that ethnic/racial differences in body Fe store susceptibility may contribute to racial and geographic disparities in MetS.
\end{abstract}

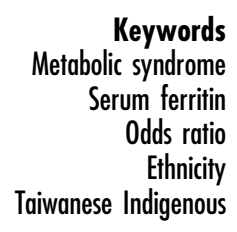

Asians and Pacific Islanders have higher circulating serum ferritin (SF) compared with Caucasians but the clinical significance of this is unclear. Both genetic ${ }^{(1,2)}$ and nongenetic factors contribute to elevated ferritin concentrations in man. Genetic predisposition is the basic reason behind the condition of high SF concentration in Caucasians ${ }^{(1)}$. Mutations (e.g. C282Y and H63D) in the haemochromatosis gene are commonly associated with high ferritin levels in the liver and in the peripheral circulation. However, Asians and Pacific Islanders have the highest geometric mean levels of SF and mean transferrin saturation compared with white counterparts despite having the lowest prevalence of C282Y homozygotes ${ }^{(1)}$. Fe overload (indicated by high $\mathrm{SF}$ levels) can cause serious health problems through parenchymal damage to organs, but primary Fe overload appears to be rare in Asians and Pacific Islanders ${ }^{(1,2)}$.
A higher prevalence of thalassaemia trait may partly explain higher mean SF levels in Asian men ${ }^{(1)}$. The non-genetic causes of elevated SF levels may also contribute to the observed racial/ethnic differences in SF levels. Factors include chronic hepatitis, excessive Fe or alcohol intake, liver disorder, metabolic syndrome and neuron degenerative diseases. High levels of SF are significantly associated with chronic inflammation. Inflammatory markers such as C-reactive protein (CRP), adiponectin and IL- 6 are positively correlated with SF concentrations ${ }^{(3)}$.

Elevated SF concentrations have recently been implicated in the pathogenesis of the metabolic syndrome (MetS) and type II diabetes ${ }^{(3-7)}$. Epidemiological studies showed that high SF levels are independently associated with risk of MetS for Caucasians ${ }^{(4,5)}$, middle-aged and elderly Chinese $^{(3)}$ and healthy Koreans ${ }^{(8)}$. This association is 
found in both genders in apparently healthy populations ${ }^{(6,7)}$. Here, the physiological function of elevated SF remains uncertain. The underlying mechanisms responsible for the rising level of ferritin in circulation as well as its effect on the diseases remain unclear. The traditional view is that ferritin may protect against Fe-induced damage because of its function as a storage protein for Fe. Ferritin has the capacity to sequester large quantities of $\mathrm{Fe}$ in a soluble, non-toxic and biologically available form, which can store up to $4500 \mathrm{Fe}$ atoms per ferritin protein complex. Free $\mathrm{Fe}$ is a potent oxidant and may cause tissue damage. This is attributed to the facts that: (i) no physiological mechanism of $\mathrm{Fe}$ excretion exists; (ii) $\mathrm{Fe}$ is an essential nutrient for all living organisms including man and pathogens; and (iii) Fe mediates the activation of reactive oxygen species. Activation of oxidative pathways causes damage to the host via several mechanisms: (i) Fe-mediated reactive oxygen species activation (e.g. DNA damage, lipid peroxidation and protein peroxidation); (ii) Fe-mediated activation of transcriptional mediators (e.g. AP1, NF-кB, endoplasmic reticulum stress mediators XBP1 and NFR1); and (iii) Fe-induced hypoxia-inducible factor 1 (HIF-1), an oxygen-sensitive transcriptional activator which promotes angiogenesis and $\mathrm{Fe}$ metabolism ${ }^{(9)}$.

Taiwan is an immigrant country and consists of four ethnic groups: Hoklo, Hakka, Mainlanders and Indigenous people, who are also known as the Mountainous ${ }^{(10)}$. Each ethnic group has developed its own unique culture, language, dietary habits and a distinctive environment. Genetically, Taiwanese aborigines are related to Austronesians ${ }^{(11)}$ and three of the four ethnic groups on Taiwan are descendents of Han Chinese. It is believed that Pacific Islanders originated in Taiwanese aborigines about 5200 years ago ${ }^{(12)}$.

There is considerable racial and/or geographical variation in the prevalence of obesity and obesity-related disease risks in Taiwan ${ }^{(13,14)}$. Taiwanese Indigenous, who originally lived in the central mountainous regions, have significantly higher prevalence of MetS compared with the Han Chinese $(32 \cdot 1 \% v, 20 \cdot 2 \%$ in men, $41 \cdot 3 \% v$. $25.5 \%$ in women $)^{(13)}$. Austronesia origin has significant independent effects on the presence of MetS $(\mathrm{OR}=2 \cdot 36$, $95 \%$ CI $1 \cdot 45,3 \cdot 87$ in men and OR $=3 \cdot 49,95 \%$ CI $1 \cdot 66$, $7 \cdot 31$ in women) after multiple adjustment for covariates ${ }^{(13)}$. The average life expectancy for Indigenous is 10 years lower than for the average Taiwanese population ${ }^{(15)}$. The life expectancy gap may contribute to the high prevalence of chronic inflammatory diseases ${ }^{(16,17)}$ and Mets ${ }^{(14)}$ among Indigenous people. The present study explored the association between SF concentration and risk of MetS in ethnically/racially diverse adult populations by use of the Nutrition and Health Survey in Taiwan (NAHSIT) 2005-2008. The objectives of the study were as follows: (i) to describe the distribution of SF level among ethnically diverse healthy populations; and (ii) to investigate the association between SF concentration and risk of MetS.

\section{Experimental methods}

\section{Study design and definition of etbnicity}

The third national nutrition and health survey in Taiwan (NAHSIT 2005-2008) was funded by the Department of Health to provide continued assessment of the health and nutrition of the people in Taiwan. The nationwide survey was conducted using a multistage, stratified and clustered sampling scheme which included a wide range of age groups across the whole of Taiwan. The present study only analysed data on adults aged $\geq 19$ years old. Four samples were collected and analysed. One sample ( $n$ 1582), which represents the Nation, with five geographical strata, was selected for inference to the whole of Taiwan. We also examined the influence of race/ethnicity and lifestyle variables (e.g. geographic isolation and dietary habits). For this reason, three additional strata were selected, including Hakka area ( $n$ 354), mountainous regions ( $n$ 330) and Penghu Island ( $n$ 372). Ethnicity was self-reported and/or defined based on the geographical location of the strata: mountainous are known as Indigenous, Hakka and Penghu Islanders refer to Han Chinese. Penghu Island represents the geographical isolation between Taiwan Island and other islands. The government of Taiwan officially recognizes distinct tribes among the Indigenous community based upon the qualifications drawn up by the Council of Indigenous Peoples (http://www.apc.gov.tw). Currently, a total of fourteen tribes have been officially recognized. The nationwide study selected thirty townships spread across the mountainous regions that are officially recognized by the Council of Indigenous Peoples. It also included Hua-lien and Tai-tung City/County in the East stratum of Taiwan. The East stratum is heavily populated with Amis and Puyuma tribes. Hakka were collected from eighteen representative townships acknowledged by the Council of Hakka people (http://www.hakka.gov.tw). Although no definitive definition of ethnicity/race exists, the NAHSIT selected a representative population representing each ethnic group according to the guidelines of each ethnic council. Details of the study design can be found elsewhere ${ }^{(18)}$. Informed consent was obtained from all participants. The study was approved by the Research Ethics Committee of Taipei Medical University (201203029) and Academia Sinica (AS-IRB01-07020) and was consistent with the World Medical Association Declaration of Helsinki (certificate of IRB approval: 201203029).

\section{Sample inclusion and exclusion}

Exclusion criteria were as follows: (i) individuals with missing data for clinical biochemistry, anthropometry and $24 \mathrm{~h}$ dietary recall; (ii) individuals with total energy intake $\geq 20920 \mathrm{~kJ} / \mathrm{d}$ ( $\geq 5000 \mathrm{kcal} / \mathrm{d}$ ) or $\leq 2092 \mathrm{~kJ} / \mathrm{d}$ ( $\leq 500 \mathrm{kcal} / \mathrm{d}$ ); and (iii) individuals with abnormal $\mathrm{SF}>500 \mathrm{ng} / \mathrm{ml}$ (as a surrogate marker for chronic inflammation). As such, a total of 1659 participants, 801 male and 858 female, were 
selected for the Nation. A total of 354 participants, 177 male and 177 female, were selected for the Hakka. A total of 330 participants, 158 male and 172 female, were selected for the mountainous, which represents Taiwanese aborigines. A total of 372 participants, 188 male and 184 female, were selected for the Penghu Islanders, which represents Han Chinese living in a different environment from the Han Chinese living on Taiwan Island.

\section{Data collection}

Information on sociodemographic variables, self-reported family health histories, $24 \mathrm{~h}$ dietary recall and lifestyle factors were obtained using a standardized questionnaire. Smoking status was divided into three categories: current smoker, past smoker and non-smoker. Questions about alcohol intake included the frequency of alcohol consumption on a weekly basis and the amount of alcohol consumed was categorized into four groups: non-drinker, light drinker $(1-20 \mathrm{~g} / \mathrm{d})$, moderate drinker ( $\geq 21-40 \mathrm{~g} / \mathrm{d})$ and heavy drinker $(\geq 41 \mathrm{~g} / \mathrm{d})$. Measurements of body weight and height, waist circumference (WC) and blood pressures are described elsewhere ${ }^{(13)}$. WC measurements were taken at the midpoint between the lower edge of the rib cage and the top of the iliac crest ${ }^{(13)}$. Dietary intake was estimated by the $24 \mathrm{~h}$ dietary recall which includes measurement of household recipes, the individual dietary recall and validation of individual dietary recall by food models. Dietary data on total energy intake, total $\mathrm{Fe}$ intake, type of $\mathrm{Fe}$ (haem $\mathrm{Fe}$ and non-haem $\mathrm{Fe}$ ) consumed, intakes of carbohydrates, protein, fats and oils, dairy products, fruit and vegetables, and use of animal or vegetable oil during cooking were obtained from $24 \mathrm{~h}$ dietary recall. Details of the data collection and data analysis have been described elsewhere ${ }^{(19)}$.

\section{Laboratory measurements}

Biochemistry data were obtained from $8 \mathrm{~h}$ fasting blood samples. Heparinized whole blood was collected for onsite measurement of $\mathrm{Hb}$. Peripheral venous blood samples were collected in tubes containing EDTA, centrifuged at $4^{\circ} \mathrm{C}$ and serum stored at $-80^{\circ} \mathrm{C}$ until analysis. Clinical biochemistry included: serum cholesterol (including total cholesterol, LDL-cholesterol and HDL-cholesterol (HDL-C)), TAG, fasting blood glucose, uric acid (UA), CRP, creatinine, homocysteine, liver function tests (glutamic-oxoacetic transaminase (GOT), glutamic-pyruvate transaminase (GPT)), amylase, blood urea nitrogen (BUN), alkaline phosphatase and Fe parameters (serum Fe, SF, total iron binding capacity (TIBC)).

\section{Definitions of Fe-deficiency anaemia and Fe overload}

Fe status was evaluated by serum Fe, transferrin saturation and SF concentrations ${ }^{(20)}$. SF was measured using a commercially available electrochemiluminescence immunoassay and was quantified by the Roche Modular
P800 analyser. Hb was measured by the cyanomethaemoglobin method (Merckotest; Merck) using a portable filter photometer calibrated with haemoglobin cyanide standard solution (Merck). Serum Fe and TIBC were measured by the ferrozine-based colorimetric method. Percentage transferrin saturation (\%TS) was calculated as serum Fe/TIBC $\times 100 \%$. Criteria for anaemia were based on the WHO cut-off values of $\mathrm{Hb}<12 \mathrm{~g} / \mathrm{dl}$ for adult females and $<13 \mathrm{~g} / \mathrm{dl}$ for adult males ${ }^{(21)}$. Fe deficiency and Fe-deficiency anaemia were defined by use of a combination of several Fe indicators as originally proposed by Cook et $a l^{(20,22,23)}$. Fe deficiency was considered if any two of the three indicators of $\mathrm{Fe}$ status showed abnormal values: $\mathrm{SF}<12 \mathrm{ng} / \mathrm{ml}, \% \mathrm{TS}<15 \%$ and $\mathrm{Hb}<13 \mathrm{mg} / \mathrm{dl}$ in men and $<12 \mathrm{mg} / \mathrm{dl}$ in women ${ }^{(20,22,23)}$. Fe-deficiency anaemia was considered if all three of the Fe indicators showed abnormal values. Fe overload was defined as SF $>300 \mathrm{ng} / \mathrm{ml}$ for men and $>200 \mathrm{ng} / \mathrm{ml}$ for women $^{(3)}$.

\section{Definition of obesity and metabolic syndrome}

Obesity and overweight were defined based on definitions used by the Department of Health in Taiwan ${ }^{(24,25)}$. Overweight was defined as a BMI $\geq 24 \mathrm{~kg} / \mathrm{m}^{2}$ and $<27 \mathrm{~kg} / \mathrm{m}^{2}$, and obesity was defined as a BMI of $\geq 27 \mathrm{~kg} / \mathrm{m}^{2}$. This definition differs from the WHO Asians' criteria which define overweight as BMI $\geq 23 \mathrm{~kg} / \mathrm{m}^{2}$ and obese as BMI $\geq 25 \mathrm{~kg} / \mathrm{m}^{2(26)}$. Central obesity was defined as a WC $\geq 90 \mathrm{~cm}$ in men and $\geq 80 \mathrm{~cm}$ in women. Hypertension was defined according to criteria in the seventh report of the Joint National Committee on Prevention, Detection, Evaluation, and Treatment of High Blood Pressure ${ }^{(27)}$.

MetS was defined based on the modified National Cholesterol Education Program Adult Treatment Panel III criteria for Asia Pacific ${ }^{(24,26)}$. Individuals with the presence of three or more of the criteria listed below were classified as having $\mathrm{MetS}^{(25)}$ : (i) $\mathrm{WC} \geq 90 \mathrm{~cm}$ in men and $\geq 80 \mathrm{~cm}$ in women; (ii) $\mathrm{TAG} \geq 150 \mathrm{mg} / \mathrm{dl}$; (iii) HDL-C $<40 \mathrm{mg} / \mathrm{dl}$ for men and $<50 \mathrm{mg} / \mathrm{dl}$ for women; (iv) systolic blood pressure $\geq 130 \mathrm{mmHg}$ or diastolic blood pressure $\geq 85 \mathrm{mmHg}$ or current use of antihypertensive drugs; and (v) fasting blood glucose $\geq 110 \mathrm{mg} / \mathrm{dl}$ or current use of antihyperglycaemic drugs.

\section{Statistical analyses}

Statistical analyses were performed using the statistical software package SAS version $9 \cdot 22$. Categorical data were presented as number and percentage. Continuous data were presented as mean and standard deviation or median and interquartile range. Due to smoothing the trend, the plot in Fig. 1 refers only to those subjects with SF level lower than $500 \mathrm{ng} / \mathrm{ml}$. Also we replace the mean by median in the figures to resolve the unstable prevalence of MetS due to small sample size in each subgroup. SF concentrations were divided into tertiles. One-way ANOVA and the $\chi^{2}$ test were used to compare 
the differences among tertile groups of SF. Multiple logistic regression models were used to estimate the odds ratios and 95\% confidence intervals for MetS and its components. The dependent variables were the presence of MetS or components of MetS. The independent covariates which may, directly or indirectly, modulate the distribution of SF levels were included in our analysis. These include: (i) dietary variables; (ii) lifestyle factors; (iii) self-reported family health history; (iv) inflammatory markers; (v) Fe parameters; and (vi) age, gender and ethnicity/race. The covariates for the adjusted OR calculation for the Nation were age, sex, BMI, UA, CRP, GOT, GPT, past smoker, hypertension, diabetes mellitus (DM) and hyperlipidaemia. The covariates for the adjusted OR calculation for the Hakka were age, sex, BMI, UA, CRP, GOT, GPT, hypertension, DM and hyperlipidaemia. The covariates for the adjusted OR calculation for the Taiwanese aborigines were age, sex, UA, CRP, GOT, GPT, hypertension, DM and hyperlipidaemia. The covariates for the adjusted OR calculation for the Penghu Islanders were age, sex, BMI, UA, CRP, GOT, GPT, hypertension, $\mathrm{DM}$ and hyperlipidaemia. All nutrient intakes were adjusted by total energy using the residual method ${ }^{(28)}$. We calculated the prevalence rate ratio as a sensitivity analysis. However, as our data did not obey the rare event assumption (having a very large variance-to-mean ratio) of Poisson regression, the over-dispersion problem would not be avoided and the estimation would be biased. An alternative, Breslow-Cox regression with assigned equal time, was used in this case ${ }^{(29)}$. This method works well if data have moderate sample size and continuous predictors ${ }^{(30)}$. A $P$ value $<0 \cdot 05$ was considered statistically significant.

\section{Results}

\section{Baseline characteristics}

Mean ages were similar among Nation (54.3 (SD 17·8) years) and the three ethnic groups $(54 \cdot 4$ (SD 17·6) years for Hakka; $56 \cdot 7$ (SD 17.8) years for Indigenous; 54.0 (SD 19.3) years for Penghu Islanders). No significant difference was found in the prevalence of Fe-deficiency anaemia (Nation: 5·2\%, Hakka: 6.6\%, Indigenous: $5 \cdot 4 \%$, Penghu Islanders: $4 \cdot 2 \%)$. Indigenous $(26 \cdot 3 \%)$ had the highest prevalence of Fe overload and Penghu Islanders $(15 \cdot 7 \%)$ the lowest. Prevalence of obesity was higher in Indigenous $(42 \cdot 4 \%)$ followed by Penghu Islanders (23.7\%), Nation (20.6\%) and Hakka (20.4\%). Similarly, Indigenous had the highest prevalence of MetS (53.3\%) followed by Penghu Islanders (35.5\%), Hakka (34.8\%) and Nation (30.9\%). Dietary Fe consumption was similar among ethnic groups (Nation: $15 \cdot 8$ (sD 17.4) $\mathrm{mg} / \mathrm{d}$, Hakka: $15 \cdot 3(\mathrm{sD} 14 \cdot 8) \mathrm{mg} / \mathrm{d}$, Indigenous: $11 \cdot 2(\mathrm{sD} 8 \cdot 9) \mathrm{mg} / \mathrm{d}$, Penghu Islanders: $13 \cdot 1$ (SD 10.5) mg/d). Amount of haem Fe and non-haem Fe intake did not differ among ethnic/racial groups.
A comparison of baseline characteristics between racial/ethnic groups according to SF tertiles is shown in Table 1 . SF tertiles were positively correlated with age and WC among ethnic groups (Table 1). SF tertiles were also significantly correlated with male gender and other Fe parameters such as TIBC, \%TS and Hb (data not shown). A positive correlation between SF tertiles and disease history among ethnic groups was also observed. Except hypertension, SF tertiles were positively correlated with hyperlipidaemia, DM, hepatitis, fatty liver and cirrhosis in Hakka. For the Indigenous, we found positive correlations between SF tertiles and hypertension and between SF tertiles and hyperlipidaemia. SF tertiles were positively correlated with disease history of hyperlipidaemia, DM and fatty liver in the Penghu Islanders. Liver function indices such as GOT and GPT were significantly correlated with SF tertiles in Hakka, Indigenous and Penghu Islanders (Table 1). We also measured dietary intake by $24 \mathrm{~h}$ dietary record. Except for Penghu Islanders, no difference between SF tertiles and dietary Fe intake was found (Table 1). SF tertiles were positively correlated with Fe consumed from animal sources and protein intake in Penghu Islanders $(P<0 \cdot 05)$. In Hakka, SF tertiles were positively correlated with vitamin $\mathrm{B}_{6}$, protein and fat intakes (all $P<0 \cdot 05$ ). Indigenous showed a positive correlation between thiamin and SF tertiles $(P<0 \cdot 05$; Table 1$)$.

\section{Distribution of serum ferritin levels stratified by age, sex and race}

Mean levels of SF (Nation: 170 (SD 311) ng/ml, Hakka: 172 (sD 188) ng/ml, Indigenous: 214 (sD 322) ng/ml, Penghu Islanders: $153(\mathrm{SD} 133) \mathrm{ng} / \mathrm{ml}$ ) and \%TS (Nation: 34.5 (SD 14.1) \%, Hakka: 33.4 (SD 12.8) \%, Indigenous: $32 \cdot 0$ (SD 16.0) \%, Penghu Islanders: $33 \cdot 8$ (sD 13.2) \%) were similar. We next examined the distribution of $\mathrm{SF}$ by age and sex stratified by ethnicity. We found that distributions of SF level were strongly associated with age and gender but not with ethnicity (Fig. 1). SF levels reached a maximum in men aged 30-49 years; by contrast, maximum levels of SF were observed in women after menopause (Fig. 1). SF levels were comparable among women of ethnic groups during the premenopausal years. After menopause, SF rose gradually and approached the levels found in males (Fig. 1).

A close association between SF distribution and prevalence of MetS was found in Indigenous men and women aged 19-59 years (Fig. 2). At ages 19-39 years, Indigenous (18.9\% of males and $11.6 \%$ of females) had the highest and Penghu Islanders $(8.9 \%$ of males and $1.9 \%$ of females) had the lowest prevalence of MetS. Prevalence of MetS was closely related to distribution of SF levels in young and middle-aged Indigenous males and females (Fig. 2). Overall, the prevalence of MetS remained relatively low among ethnic groups until after the fifth decade of life, after which all groups exhibited a steep rise in MetS and a concomitant decline in SF levels (Fig. 2). 
Table 1 Comparison of baseline characteristics between racial/ethnic groups in relation to SF tertiles; healthy Taiwanese men and women aged $\geq 19$ years $(n 2638)$

\begin{tabular}{|c|c|c|c|c|c|c|c|c|c|c|c|c|c|c|c|c|c|c|}
\hline & \multicolumn{6}{|c|}{ Hakka } & \multicolumn{6}{|c|}{ Indigenous } & \multicolumn{6}{|c|}{ Penghu Islanders } \\
\hline & \multicolumn{6}{|c|}{ SF tertile } & \multicolumn{6}{|c|}{ SF tertile } & \multicolumn{6}{|c|}{ SF tertile } \\
\hline & \multicolumn{2}{|c|}{$1(n 110)$} & \multicolumn{2}{|c|}{$2(n 111)$} & \multicolumn{2}{|c|}{$3(n 113)$} & \multicolumn{2}{|c|}{$1(n$ 104) } & \multicolumn{2}{|c|}{$2(n 105)$} & \multicolumn{2}{|c|}{$3(n 107)$} & \multicolumn{2}{|c|}{$1(n 114)$} & \multicolumn{2}{|c|}{$2(n 114)$} & \multicolumn{2}{|c|}{$3(n 117)$} \\
\hline & $\begin{array}{l}\text { Mean } \\
\text { or } n\end{array}$ & $\begin{array}{l}\text { SD } \\
\text { or } \%\end{array}$ & $\begin{array}{l}\text { Mean } \\
\text { or } n\end{array}$ & $\begin{array}{l}\text { SD } \\
\text { or } \%\end{array}$ & $\begin{array}{l}\text { Mean } \\
\text { or } n\end{array}$ & $\begin{array}{l}\text { SD } \\
\text { or } \%\end{array}$ & $\begin{array}{l}\text { Mean } \\
\text { or } n\end{array}$ & $\begin{array}{l}\text { SD } \\
\text { or } \%\end{array}$ & $\begin{array}{l}\text { Mean } \\
\text { or } n\end{array}$ & $\begin{array}{l}\text { SD } \\
\text { or } \%\end{array}$ & $\begin{array}{l}\text { Mean } \\
\text { or } n\end{array}$ & $\begin{array}{l}\text { SD } \\
\text { or } \%\end{array}$ & $\begin{array}{l}\text { Mean } \\
\text { or } n\end{array}$ & $\begin{array}{l}\text { SD } \\
\text { or } \%\end{array}$ & $\begin{array}{l}\text { Mean } \\
\text { or } n\end{array}$ & $\begin{array}{l}\text { SD } \\
\text { or } \%\end{array}$ & $\begin{array}{l}\text { Mean } \\
\text { or } n\end{array}$ & $\begin{array}{l}\text { SD } \\
\text { or } \%\end{array}$ \\
\hline Age (years) & $50 \cdot 0$ & $18 \cdot 2$ & $56 \cdot 6$ & $17 \cdot 5$ & $55 \cdot 5^{\star}$ & $15 \cdot 9$ & $50 \cdot 2$ & $18 \cdot 9$ & $59 \cdot 6$ & $19 \cdot 4$ & $59 \cdot 5^{\star \star \star \star}$ & $16 \cdot 3$ & $46 \cdot 9$ & $19 \cdot 7$ & $57 \cdot 5$ & $17 \cdot 5$ & $57 \cdot 4^{\star \star \star *}$ & $17 \cdot 8$ \\
\hline WC $(\mathrm{cm})$ & $79 \cdot 8$ & $10 \cdot 4$ & $84 \cdot 3$ & $10 \cdot 3$ & $86 \cdot 9^{* \star \star \star}$ & $9 \cdot 7$ & $85 \cdot 9$ & $11 \cdot 1$ & $87 \cdot 0$ & $11 \cdot 2$ & $90 \cdot 1^{\star \star}$ & $12 \cdot 2$ & $78 \cdot 7$ & $11 \cdot 1$ & $84 \cdot 8$ & $12 \cdot 2$ & $86 \cdot 6^{\star \star \star \star}$ & $9 \cdot 3$ \\
\hline $\mathrm{SF}(\mathrm{ng} / \mathrm{ml})$ & $34 \cdot 2$ & $20 \cdot 4$ & $121 \cdot 3$ & $27 \cdot 7$ & $355 \cdot 8^{\star * \star *}$ & $220 \cdot 8$ & $39 \cdot 7$ & $24 \cdot 0$ & 133.5 & $35 \cdot 9$ & $463 \cdot 5^{\star \star \star \star}$ & $454 \cdot 5$ & $38 \cdot 5$ & $23 \cdot 5$ & $117 \cdot 3$ & $25 \cdot 9$ & $298 \cdot 5^{\star \star \star \star}$ & $125 \cdot 7$ \\
\hline Hypertension $(n, \%)$ & 27 & $24 \cdot 55$ & 37 & $33 \cdot 33$ & 37 & $32 \cdot 74$ & 40 & $38 \cdot 46$ & 55 & $52 \cdot 88$ & $63^{\star *}$ & $58 \cdot 88$ & 30 & $26 \cdot 32$ & 49 & $42 \cdot 90$ & 42 & $35 \cdot 90$ \\
\hline Hyperlipidaemia $(n, \%)$ & 16 & $14 \cdot 55$ & 28 & $25 \cdot 23$ & $44^{\star \star \star}$ & 38.94 & 8 & $8 \cdot 79$ & 7 & $7 \cdot 69$ & $19^{* \star}$ & $20 \cdot 65$ & 4 & $3 \cdot 88$ & 12 & $11 \cdot 43$ & $12^{*}$ & $11 \cdot 43$ \\
\hline $\mathrm{DM}(n, \%)$ & 12 & $10 \cdot 91$ & 19 & $17 \cdot 12$ & $25^{\star}$ & $22 \cdot 12$ & 48 & $46 \cdot 15$ & 58 & $55 \cdot 24$ & 57 & $53 \cdot 27$ & 27 & $23 \cdot 68$ & 49 & $42 \cdot 98$ & $55^{\star \star \star \star}$ & $47 \cdot 01$ \\
\hline Hepatitis ( $n, \%)$ & 1 & 0.97 & 7 & $6 \cdot 73$ & $8^{\star}$ & $7 \cdot 55$ & 9 & $9 \cdot 00$ & 8 & $8 \cdot 16$ & 11 & $11 \cdot 22$ & 7 & $6 \cdot 36$ & 7 & $6 \cdot 36$ & 11 & $9 \cdot 65$ \\
\hline Fatty liver $(n, \%)$ & 1 & 0.97 & 9 & $8 \cdot 65$ & $10^{* *}$ & $9 \cdot 52$ & 8 & $8 \cdot 51$ & 5 & $5 \cdot 49$ & 8 & 8.99 & 4 & $3 \cdot 85$ & 6 & $5 \cdot 83$ & $17^{\star \star \star}$ & $16 \cdot 35$ \\
\hline Cirrhosis $(n, \%)$ & 0 & 0 & 0 & 0 & $2^{*}$ & $1 \cdot 89$ & 4 & $4 \cdot 30$ & 0 & 0 & 2 & $2 \cdot 27$ & 1 & 0.97 & 1 & 0.97 & 0 & 0 \\
\hline CRP (mg/l) & 0.22 & 0.42 & 0.28 & 0.48 & 0.31 & 0.46 & 0.32 & 0.91 & 0.49 & $1 \cdot 07$ & 0.47 & $1 \cdot 07$ & $0 \cdot 19$ & 0.50 & 0.29 & $0 \cdot 74$ & $0 \cdot 27$ & 0.43 \\
\hline GOT (U/I) & $19 \cdot 8$ & $6 \cdot 5$ & $22 \cdot 3$ & $7 \cdot 8$ & $29 \cdot 8^{\star \star \star}$ & $35 \cdot 4$ & $28 \cdot 7$ & $33 \cdot 3$ & $25 \cdot 5$ & $16 \cdot 9$ & $36 \cdot 0^{*}$ & $26 \cdot 8$ & $19 \cdot 6$ & $5 \cdot 5$ & $24 \cdot 0$ & $9 \cdot 0$ & $27 \cdot 6^{\star \star * \star}$ & $19 \cdot 7$ \\
\hline GPT (U/I) & $16 \cdot 3$ & $14 \cdot 0$ & $19 \cdot 3$ & $11 \cdot 6$ & $31 \cdot 4^{\star \star * *}$ & $37 \cdot 0$ & $23 \cdot 3$ & $27 \cdot 8$ & $23 \cdot 6$ & $27 \cdot 6$ & $32 \cdot 2^{*}$ & $29 \cdot 4$ & $17 \cdot 2$ & $10 \cdot 5$ & $22 \cdot 7$ & $13 \cdot 9$ & $28 \cdot 1^{\star \star \star \star}$ & $22 \cdot 1$ \\
\hline Thiamin intake (mg/d) & $1 \cdot 11$ & 0.75 & $1 \cdot 33$ & 0.95 & $1 \cdot 30$ & $0 \cdot 70$ & 0.91 & 0.57 & 1.09 & 0.90 & $1 \cdot 21^{*}$ & $1 \cdot 36$ & $1 \cdot 11$ & 0.78 & $1 \cdot 07$ & 0.82 & $1 \cdot 21^{*}$ & 0.94 \\
\hline Riboflavin intake (mg/d) & $1 \cdot 40$ & $1 \cdot 28$ & $1 \cdot 58$ & $1 \cdot 51$ & $1 \cdot 39$ & $1 \cdot 15$ & 1.06 & 0.89 & 0.98 & $0 \cdot 82$ & 0.95 & $0 \cdot 80$ & $1 \cdot 17$ & 0.76 & $1 \cdot 41$ & 1.46 & $1 \cdot 56$ & 1.57 \\
\hline Vitamin $B_{6}$ intake $(\mathrm{mg} / \mathrm{d})$ & $1 \cdot 59$ & 0.80 & $1 \cdot 83$ & $1 \cdot 20$ & $1 \cdot 98^{\star \star}$ & $1 \cdot 27$ & $1 \cdot 54$ & 0.99 & $1 \cdot 56$ & $1 \cdot 34$ & $1 \cdot 57$ & $1 \cdot 18$ & $1 \cdot 68$ & $1 \cdot 05$ & $1 \cdot 61$ & $1 \cdot 11$ & 1.91 & $1 \cdot 36$ \\
\hline Vitamin $B_{12}$ intake $(\mathrm{mg} / \mathrm{d})$ & 8.95 & $33 \cdot 4$ & 5.99 & $15 \cdot 8$ & $6 \cdot 87$ & $13 \cdot 8$ & $5 \cdot 79$ & $18 \cdot 1$ & $6 \cdot 13$ & $29 \cdot 4$ & $5 \cdot 49$ & $10 \cdot 4$ & $6 \cdot 28$ & $11 \cdot 1$ & $5 \cdot 8$ & $7 \cdot 3$ & $11 \cdot 6$ & $22 \cdot 2$ \\
\hline $\begin{array}{l}\text { Vitamin C intake }(\mathrm{mg} / \mathrm{d}) \\
\text { Fe intake }(\mathrm{mg} / \mathrm{d})\end{array}$ & 157 & 147 & 164 & 128 & 176 & 114 & 139 & 133 & 135 & 153 & 128 & 145 & 159 & 135 & 167 & 183 & 155 & 129 \\
\hline All & $15 \cdot 6$ & $21 \cdot 9$ & $15 \cdot 2$ & $9 \cdot 7$ & $15 \cdot 0$ & $10 \cdot 5$ & $11 \cdot 6$ & $8 \cdot 0$ & $11 \cdot 3$ & $11 \cdot 7$ & $11 \cdot 0$ & $6 \cdot 7$ & $13 \cdot 6$ & $12 \cdot 5$ & $11 \cdot 8$ & $7 \cdot 8$ & $14 \cdot 4$ & $10 \cdot 9$ \\
\hline Plant & $11 \cdot 8$ & $21 \cdot 2$ & $11 \cdot 2$ & $8 \cdot 9$ & $10 \cdot 0$ & $7 \cdot 1$ & $8 \cdot 1$ & $6 \cdot 2$ & $6 \cdot 9$ & $4 \cdot 8$ & $7 \cdot 5$ & $5 \cdot 4$ & $9 \cdot 8$ & $11 \cdot 9$ & $8 \cdot 8$ & $6 \cdot 8$ & $9 \cdot 2$ & $7 \cdot 7$ \\
\hline Animal & 3.5 & 3.5 & $3 \cdot 7$ & 3.5 & $4 \cdot 7$ & 6.5 & $3 \cdot 3$ & $4 \cdot 1$ & $4 \cdot 0$ & $9 \cdot 1$ & $3 \cdot 3$ & 3.9 & $3 \cdot 6$ & $3 \cdot 1$ & $2 \cdot 9$ & $2 \cdot 7$ & $5 \cdot 0^{\star}$ & $5 \cdot 9$ \\
\hline Protein intake $(\mathrm{g} / \mathrm{d})$ & $69 \cdot 7$ & $34 \cdot 2$ & $74 \cdot 5$ & $38 \cdot 1$ & $82 \cdot 9^{\star}$ & $46 \cdot 0$ & $60 \cdot 9$ & $34 \cdot 7$ & $66 \cdot 3$ & $57 \cdot 5$ & $66 \cdot 7$ & $47 \cdot 0$ & $76 \cdot 7$ & $40 \cdot 0$ & $72 \cdot 8$ & $38 \cdot 1$ & $90 \cdot 2^{*}$ & $58 \cdot 0$ \\
\hline Fat intake $(\mathrm{g} / \mathrm{d})$ & $53 \cdot 3$ & $32 \cdot 6$ & $64 \cdot 4$ & $54 \cdot 2$ & $71 \cdot 2^{\star \star}$ & $52 \cdot 1$ & $60 \cdot 1$ & $49 \cdot 1$ & $61 \cdot 9$ & $60 \cdot 4$ & $70 \cdot 5$ & $80 \cdot 3$ & $64 \cdot 4$ & $46 \cdot 5$ & $54 \cdot 0$ & $42 \cdot 8$ & $69 \cdot 6$ & $64 \cdot 1$ \\
\hline Fibre intake $(g / d)$ & $17 \cdot 8$ & $22 \cdot 4$ & $17 \cdot 8$ & $12 \cdot 8$ & $18 \cdot 6$ & $15 \cdot 9$ & $12 \cdot 7$ & $8 \cdot 3$ & $11 \cdot 0$ & $8 \cdot 2$ & $11 \cdot 5$ & $7 \cdot 3$ & $15 \cdot 4$ & $10 \cdot 6$ & $14 \cdot 7$ & $10 \cdot 8$ & $15 \cdot 1$ & $11 \cdot 4$ \\
\hline Carbohydrate intake (g/d) & 243 & 122 & 248 & 154 & 249 & 137 & 215 & 113 & 205 & 118 & 210 & 118 & 241 & 136 & 241 & 117 & 262 & 142 \\
\hline
\end{tabular}

SF, serum ferritin; WC, waist circumference; DM, diabetes mellitus; CRP, C-reactive protein; GOT, glutamic-oxoacetic transaminase; GPT, glutamic-pyruvate transaminase.

SF, serum ferritin; WC, waist circumference; DM, diabet
${ }^{*} P<0 \cdot 05,{ }^{* *} P<0.01,{ }^{* * *} P<0.001,{ }^{* * \star *} P<0.0001$ 


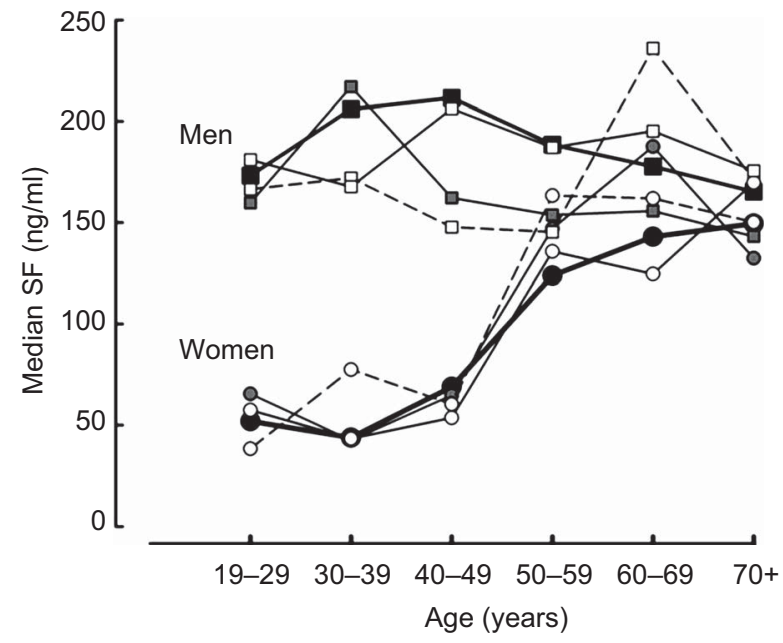

Fig. 1 Distribution of serum ferritin (SF) level by decade of age for healthy Taiwanese men and women aged $\geq 19$ years $(n$ 2638) stratified by ethnicity (Nation: $-\longrightarrow$ (men), $-\longrightarrow$ (women); Hakka: $-\square-$ (men), -o- (women); Indigenous: -- $\square-$ (men), --o-(women); Penghu Islander: $-\square-($ men), $-0-$ (women))

\section{Association between serum ferritin and metabolic syndrome and its components}

A best-fit multivariable model was used to assess the association between SF and risk of MetS among ethnic groups. The adjusted odds for MetS was OR $=1.92(95 \%$ CI $1 \cdot 31,2 \cdot 81$ ) for the Nation for individuals in the highest $\mathrm{SF}$ tertile compared with those in the lowest, after adjusting for the age, sex, BMI, inflammatory markers (amylase, UA, CRP, GOT, GPT), lifestyle factors (smoking, betel-nut consumption) and family history of chronic diseases (hypertension, DM, hyperlipidaemia). The univariate logistic regression model identified Austronesia origin as independently associated with risk of MetS $(\mathrm{OR}=2 \cdot 61,95 \%$ CI $2 \cdot 02,3 \cdot 36)$. Multiple logistic regression analysis showed the odds was substantially higher for Indigenous people $(\mathrm{OR}=2 \cdot 11,95 \%$ CI $1 \cdot 02,4 \cdot 36$; Table 2). By contrast, Hakka and Penghu Islanders yield the lowest risks ( $\mathrm{OR}=0 \cdot 87,95 \% \mathrm{CI} 0 \cdot 34,2 \cdot 21$ and $\mathrm{OR}=1 \cdot 85,95 \%$ CI $0 \cdot 84,4 \cdot 09$, respectively). We also show the prevalence rate ratio in Table 2 as sensitivity analysis. The estimation ratio was similar and the confidence interval was smaller (Table 2). For Indigenous, being in the highest SF tertile was significantly correlated with fasting glucose $(\mathrm{OR}=2 \cdot 56,95 \%$ CI $1 \cdot 35,4 \cdot 86)$, serum TAG $(\mathrm{OR}=2 \cdot 17,95 \% \mathrm{CI} 1 \cdot 22,3 \cdot 85)$ and serum HDL-C $(\mathrm{OR}=2 \cdot 08,95 \%$ CI $1 \cdot 15,3 \cdot 75$; Table 3$)$.

\section{Discussion}

Our study raises the possibility that racial differences in SF tolerance may contribute to racial or geographic disparities in MetS. Fe overload and MetS are both chronic process that are known to be closely related to lifestyle (a)

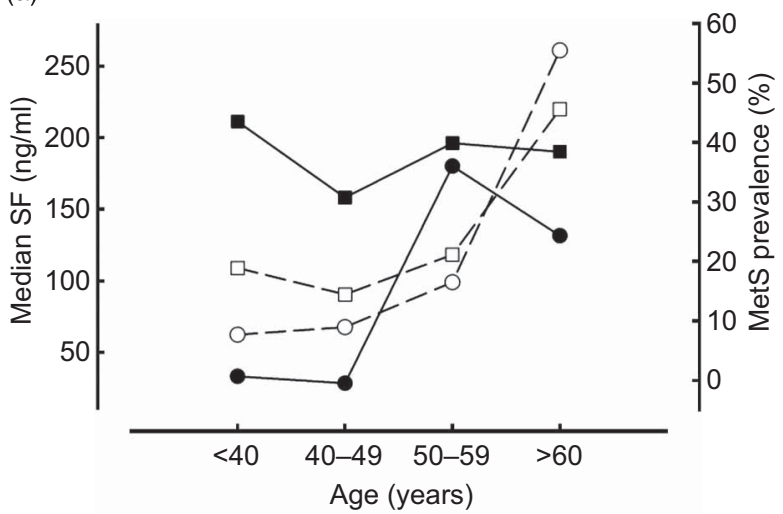

(b)

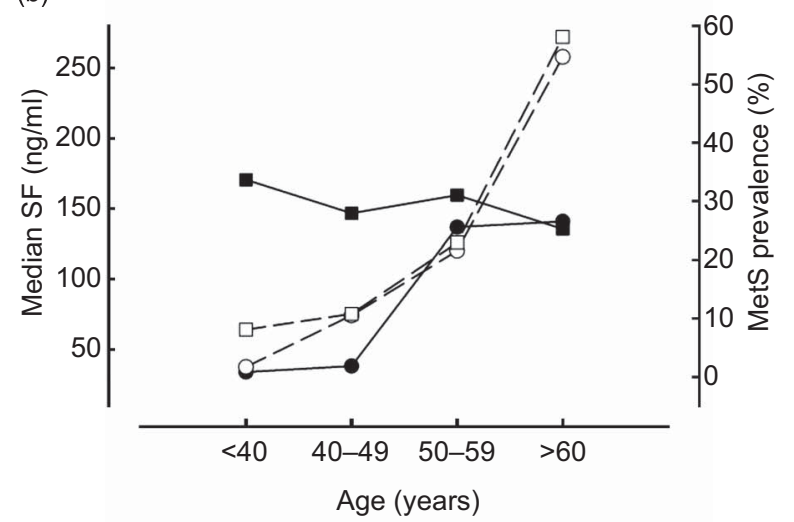

(c)

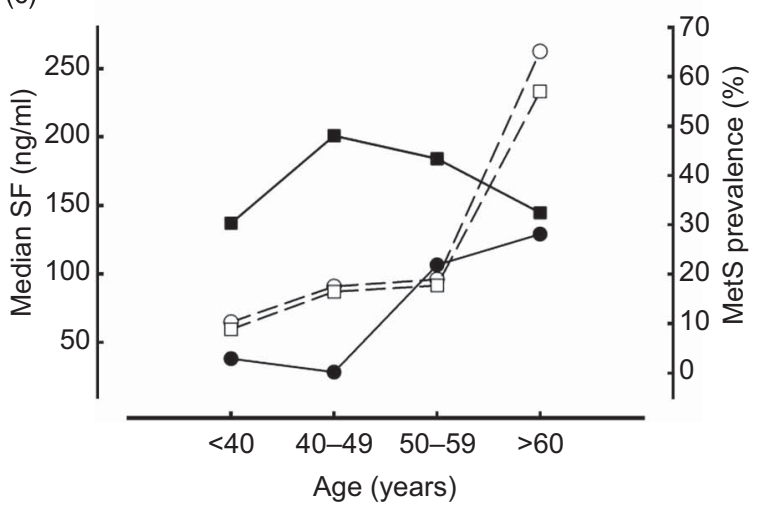

Fig. 2 Association between serum ferritin (SF) level ( $-\longrightarrow$, men; --, women) and metabolic syndrome (MetS) prevalence (-- ---, men; --o--, women) by decade of age for healthy Taiwanese men and women aged $\geq 19$ years $(n 2638)$ according to ethnic group: (a) Indigenous; (b) Hakka; (c) Penghu Islanders

and the life cycle. It has been known for some time that the prevalences of obesity and MetS are higher in Indigenous people than in Han Chinese in Taiwan ${ }^{(13)}$. This motivated us to evaluate the effect of SF on MetS in relation to ethnicity. Although restricted to a small sample size, our study demonstrated that the odds for MetS was substantially higher for Indigenous people in the highest tertile of SF than for those in the lowest (OR $=2 \cdot 11,95 \%$ CI $1 \cdot 02,4 \cdot 36$ ). By contrast, Hakka and Penghu islanders 
Table 2 Risk for MetS of racial/ethnic groups in relation to SF tertiles; healthy Taiwanese men and women aged $\geq 19$ years $(n$ 2638)

\begin{tabular}{|c|c|c|c|c|c|c|}
\hline & \multicolumn{5}{|c|}{ SF tertile } & \multirow[b]{3}{*}{$P$ for trend } \\
\hline & \multirow{2}{*}{$\frac{1}{\text { Ref. }}$} & \multicolumn{2}{|c|}{2} & \multicolumn{2}{|c|}{3} & \\
\hline & & OR & $95 \% \mathrm{Cl}$ & OR & $95 \% \mathrm{Cl}$ & \\
\hline Hakkat,‡ & $1 \cdot 000$ & 0.530 & $0 \cdot 205,1 \cdot 367$ & $0 \cdot 871$ & $0 \cdot 343,2 \cdot 213$ & 0.366 \\
\hline Indigenous§,|| & $1 \cdot 000$ & $1 \cdot 498$ & $0.759,2.955$ & $2 \cdot 109$ & $1 \cdot 021,4 \cdot 358$ & $0 \cdot 129$ \\
\hline \multirow[t]{2}{*}{ Penghu Islanders $\Phi, t \dagger$} & $1 \cdot 000$ & $1 \cdot 014$ & $0 \cdot 450,2 \cdot 285$ & $1 \cdot 847$ & $0.835,4.087$ & $0 \cdot 179$ \\
\hline & & PRR & $95 \% \mathrm{Cl}$ & PRR & $95 \% \mathrm{Cl}$ & \\
\hline Hakkat,‡ & $1 \cdot 000$ & 0.922 & $0.549,1.549$ & $1 \cdot 144$ & $0 \cdot 709,1 \cdot 845$ & 0.669 \\
\hline Indigenous§,\| & 1.000 & $1 \cdot 326$ & $0.844,2 \cdot 083$ & 1.575 & $1 \cdot 020,2 \cdot 432$ & $0 \cdot 122$ \\
\hline Penghu Islanders & 1.000 & 0.999 & $0.608,1.639$ & $1 \cdot 319$ & $0 \cdot 813,2 \cdot 141$ & 0.344 \\
\hline
\end{tabular}

MetS, metabolic syndrome; SF, serum ferritin; Ref., reference category; PRR, prevalence rate ratio; UA, uric acid; CRP, C-reactive protein; GOT, glutamicoxoacetic transaminase; GPT, glutamic-pyruvate transaminase; DM, diabetes mellitus.

tHakka SF tertile cut-off values by gender: $110 \cdot 3 \mathrm{ng} / \mathrm{ml}, 199 \cdot 6 \mathrm{ng} / \mathrm{ml}$ for males; $43.3 \mathrm{ng} / \mathrm{ml}, 139 \cdot 1 \mathrm{ng} / \mathrm{ml}$ for females.

‡Hakka adjusted for age, sex, BMI, inflammation (UA, CRP, GOT, GPT) and self-reported disease history (DM, hypertension, hyperlipidaemia, fatty liver disease).

§Indigenous SF tertile cut-off values by gender: $123 \cdot 2 \mathrm{ng} / \mathrm{ml}, 260 \cdot 4 \mathrm{ng} / \mathrm{ml}$ for males; $52 \cdot 4 \mathrm{ng} / \mathrm{ml}, 147 \cdot 6 \mathrm{ng} / \mathrm{ml}$ for females.

IIIndigenous adjusted for age, sex, inflammation (CRP, GOT, GPT) and self-reported disease history (DM, hypertension, hyperlipidaemia).

-Penghu Islanders SF tertile cut-off values by gender: $114.9 \mathrm{ng} / \mathrm{ml}, 234 \cdot 8 \mathrm{ng} / \mathrm{ml}$ for males; $47 \cdot 2 \mathrm{ng} / \mathrm{ml}, 115 \cdot 4 \mathrm{ng} / \mathrm{ml}$ for females.

t+Penghu Islanders: adjusted for age, sex, BMI, inflammation (CRP, GOT, GPT) and self-reported disease history (DM, hypertension, hyperlipidaemia).

Table 3 Adjusted odds ratios and $95 \%$ confidence intervals for the individual components of MetS by SF tertile among Indigenous people; healthy Taiwanese men and women aged $\geq 19$ years $(n 330)$

\begin{tabular}{|c|c|c|c|c|c|c|}
\hline \multirow[b]{3}{*}{ MetS component } & \multicolumn{5}{|c|}{ SF tertilet, $\ddagger$} & \multirow[b]{3}{*}{$P$ for trenc } \\
\hline & \multirow{2}{*}{$\frac{1}{\text { Ref. }}$} & \multicolumn{2}{|c|}{2} & \multicolumn{2}{|c|}{3} & \\
\hline & & Adjusted OR & $95 \% \mathrm{Cl}$ & Adjusted OR & $95 \% \mathrm{Cl}$ & \\
\hline Blood pressure $\geq 135 / 85 \mathrm{mmHg}$ & $1 \cdot 000$ & 0.733 & $0 \cdot 401,1 \cdot 338$ & $1 \cdot 696$ & $0.920,3 \cdot 128$ & 0.078 \\
\hline Fasting serum glucose $\geq 110 \mathrm{mg} / \mathrm{dl}$ & $1 \cdot 000$ & $1 \cdot 328$ & $0 \cdot 744,2 \cdot 370$ & $2 \cdot 558$ & $1 \cdot 346,4 \cdot 859$ & 0.022 \\
\hline $\mathrm{TAG} \geq 150 \mathrm{mg} / \mathrm{dl}$ & $1 \cdot 000$ & $1 \cdot 165$ & $0.652,2.082$ & $2 \cdot 165$ & $1 \cdot 218,3 \cdot 850$ & 0.049 \\
\hline $\mathrm{HDL}-\mathrm{C}<40 \mathrm{mg} / \mathrm{dll}$ (men), $<50 \mathrm{mg} / \mathrm{dl}$ (women) & $1 \cdot 000$ & $1 \cdot 737$ & $0 \cdot 968,3 \cdot 117$ & $2 \cdot 076$ & $1 \cdot 150,3 \cdot 745$ & 0.040 \\
\hline$W C \geq 90 \mathrm{~cm}$ (men), $\geq 80 \mathrm{~cm}$ (women) & $1 \cdot 000$ & $1 \cdot 087$ & $0.591,1.999$ & $1 \cdot 846$ & $0.978,3.484$ & $0 \cdot 147$ \\
\hline
\end{tabular}

MetS, metabolic syndrome; SF, serum ferritin; Ref., reference category; HDL-C, HDL-cholesterol.

tAge- and gender-adjusted.

łIndigenous SF tertile cut-off values by gender: $123 \cdot 2 \mathrm{ng} / \mathrm{ml}, 260 \cdot 4 \mathrm{ng} / \mathrm{ml}$ for males; $52 \cdot 4 \mathrm{ng} / \mathrm{ml}, 147 \cdot 6 \mathrm{ng} / \mathrm{ml}$ for females.

yielded the lowest risks $(\mathrm{OR}=0 \cdot 87,95 \% \mathrm{CI} 0 \cdot 34,2 \cdot 21$ and $\mathrm{OR}=1 \cdot 85,95 \% \mathrm{CI} 0 \cdot 84,4 \cdot 09$, respectively). This difference is not explained by the SF concentrations per se because both Han Chinese and Indigenous people had similar crude and adjusted SF concentrations. A 4-year follow-up study in 1038 Finnish men aged 42-60 years by Salonen et al. demonstrated that even mildly increased body Fe stores predict the development of non-insulin dependent diabetes ${ }^{(31)}$. A recent study showed that SF or ferritin L-chain/H-chain induces pro-inflammatory cytokine secretions via NF- $\kappa$ B pathways in rat hepatic stellate cells ${ }^{(32)}$. Our in vitro data confirmed the pro-inflammatory activity of SF even in physiological concentrations (JS Chang, unpublished results). These data raise the possibility that SF per se acts as a signalling molecule and long-term exposure to elevated SF, even mild elevation, may have a profound effect on MetS. Our study showed that Austronesian origin did not predispose Indigenous people to high SF levels compared with Han Chinese. However, we noticed that SF concentrations were slightly higher in young Indigenous men aged $>19$ to $<40$ years compared with Hakka and Penghu Islander men, although it did not reach statistical significance (Fig. 2). Accordingly, young Indigenous men aged $>19$ to $<40$ years had higher prevalence of MetS than Hakka and Penghu Islanders (Fig. 2). These data imply that perhaps earlier exposure to mildly elevated SF levels may sensitize young Indigenous men to MetS. A follow-up study is required in the young Indigenous population to clarify the causeand-effect relationship between SF and MetS and the racial disparities in MetS.

By the studying association between SF levels and DM in six racial/ethnic groups, Acton et al. showed a positive association between SF levels and DM risk in women across all racial groups ${ }^{(33)}$. A notable exception was in Asian and Pacific Islander men. Asian and Pacific Islander men with SF concentrations in quintile 2 had increased risk for DM compared with those with the lowest SF quintile. The relationship between SF levels and DM in Asian/Pacific Islander men was not linear but bimodal, indicating that Asian/Pacific Islander men were more susceptible to SF. Although we were unable to conduct 
gender-specific examination due to the limited sample size, our data were partially in agreement with Acton et al.'s findings ${ }^{(33)}$.

To our knowledge, few studies have investigated the relationship between SF levels and MetS in a racially/ ethnically diverse population. Blacks ${ }^{(34)}$, Asians and Pacific Islanders ${ }^{(1,2)}$ are known to have higher SF concentrations than whites. However, a series of questions are also raised by these observations. Is genetic predisposition the basic reason behind the condition of high SF concentrations among Asians, blacks and Pacific Islanders compared with whites? Or are lifestyle-associated factors (e.g. dietary Fe intake, obesity, hepatic health) responsible for the racial disparities in hyperferritinaemia? Will high levels of SF predispose Asians to MetS? Zacharski et al. showed that different patterns of SF level exist according to age, sex and race (white/Hispanic $v$. black) ${ }^{(34)}$. However, we did not observe a similar association between SF concentrations and race/ethnicity (Han Chinese $v$. Austronesia origin). By contrast, an ageassociated increase in body Fe stores was noted in all racial groups in our study.

SF concentration normally reflects body Fe stores in healthy individuals. However, SF is also an acute-phase protein and abnormal SF levels are commonly associated with chronic inflammation. Our first attempt was to understand whether SF distribution differed among ethnic groups; particularly, before the onset of MetS. We found there were no differences in crude mean SF concentrations among ethnic groups by decade of age for women and men (data not shown). We next attempted to minimize the potential confounding factor by excluding those individuals with $\mathrm{SF}>500 \mathrm{ng} / \mathrm{ml}$ (as a surrogate marker of chronic inflammation) or SF $>500 \mathrm{ng} / \mathrm{ml}$ and family health history for liver diseases and diabetes. Both exclusion criteria did not change the distribution of SF by age, sex and stratified by race. Due to the restricted small sample size among ethnic groups, we decided not to exclude individuals with self-reported family health histories or those on medications for further analysis. However, we cannot rule out residual confounding effects due to failure to adjust for inflammatory conditions.

Our study is limited by the small sample size, particularly for the three ethnic groups, and confined by its cross-sectional nature. In order to understand the casual relationship between SF levels and MetS, a longitudinal study is necessary in order to understand if changes in Fe stores over time predict disease susceptibility in an apparently healthy population. Alternatively, future work should investigate the association between SF concentrations and risk of MetS at younger ages. Obese children and teenagers have relatively low grade of inflammation compared with obese adults. Thus, such a study will allow us to clarify the relevant contribution of certain environmental factors to the exaggerated $\mathrm{Fe}$ accumulation and disease risk. In addition, we rely on geographical location for the category of ethnicity, which may not be as accurate as the self-report of identity. However, previous data showed that $>80 \%$ of people living in the mountainous strata had aboriginal ancestry and $\sim 70-80 \%$ of people living in Hakka strata were of Hakka origin. Such variations should lead the association towards the null. Also, the use of a $24 \mathrm{~h}$ dietary record may be not of sufficient length to obtain reliable data on Fe intakes.

\section{Conclusion}

Our study showed that the distribution of SF levels was comparable among ethnic groups; however, Indigenous people in the highest SF tertile were at highest risk for developing MetS than those in the lowest SF tertile. This association was limited to the Austronesia origins but not to Hakka and Penghu Islanders. Persons of Austronesia origin may be more sensitive to the change in levels of SF compared with Han Chinese. Future studies investigating the 'cause-and-effect' relationship between changes of SF distributions and risk of MetS among young ethnic groups are warranted.

\section{Acknowledgements}

Sources of funding: The Third Nutrition and Health Survey in Taiwan (NAHSIT 2005-2008, Adults) was sponsored by the Department of Health in Taiwan (DOH94-FS-6-4). J.-S.C. was supported by grant TMU100AE1-B09. Conflicts of interest: The authors have no financial relationships relevant to this article to disclose. Authors' contributions: J.-S.C. conceptualized and designed the study, drafted the initial manuscript and approved the final manuscript as submitted. S.-M.L. participated in Fe biochemistry analysis. J.C.-J.C. supervised data collection and carried out the initial data analyses. Y.-C.C. participated in data collection and pro-inflammatory cytokines analysis. C.-M.W. participated in biochemistry analysis of MetS components. N.-H.C. participated in data collection and analysis of $24 \mathrm{~h}$ dietary records. W.-H.P. conceptualized the National Nutrition and Health Survey and approved the final manuscript as submitted. C.-W.B. carried out the initial analyses and critically reviewed the manuscript. Acknowledgements: The authors express their sincere appreciation to the study participants. They also wish to thank staff from the Research Center for Humanities and Social Sciences, Center for Survey Research, Academia Sinica and Dr Wen-Han Pan and Dr Su-Hao Tu (Directors).

\section{References}

1. Adams PC, Reboussin DM, Barton JC et al. (2005) Hemochromatosis and iron-overload screening in a racially diverse population. $N$ Engl J Med 352, 1769-1778. 
2. Harris EL, McLaren CE, Reboussin DM et al. (2007) Serum ferritin and transferrin saturation in Asians and Pacific Islanders. Arch Intern Med 167, 722-726.

3. Sun L, Franco OH, Hu FB et al. (2008) Ferritin concentrations, metabolic syndrome, and type 2 diabetes in middleaged and elderly chinese. J Clin Endocrinol Metab 93, 4690-4696.

4. Bozzini C, Girelli D, Olivieri O et al. (2005) Prevalence of body iron excess in the metabolic syndrome. Diabetes Care 28, 2061-2063.

5. Jehn M, Clark JM \& Guallar E (2004) Serum ferritin and risk of the metabolic syndrome in US adults. Diabetes Care 27, $2422-2428$

6. Rajpathak S, Ma J, Manson J et al. (2006) Iron intake and the risk of type 2 diabetes in women: a prospective cohort study. Diabetes Care 29, 1370-1376.

7. Ryoo JH, Kim MG, Lee DW et al. (2011) The relationship between serum ferritin and metabolic syndrome in healthy Korean men. Diabetes Metab Res Rev 27, 597-603.

8. Lee BK, Kim Y \& Kim YI (2011) Association of serum ferritin with metabolic syndrome and diabetes mellitus in the South Korean general population according to the Korean National Health and Nutrition Examination Survey 2008. Metabolism 60, 1416-1424.

9. Huang X (2003) Iron overload and its association with cancer risk in humans: evidence for iron as a carcinogenic metal. Mutat Res 533, 153-171.

10. Tsai Y (2010) Geneticizing ethnicity: a study on the 'Taiwan Bio-Bank'. East Asian Sci Technol Society 4, 433-455.

11. Friedlaender JS, Friedlaender FR, Reed FA et al. (2008) The genetic structure of Pacific Islanders. PLoS Genet 4, e19.

12. Gray RD, Drummond AJ \& Greenhill SJ (2009) Language phylogenies reveal expansion pulses and pauses in Pacific settlement. Science 323, 479-483.

13. Pan WH, Lee MS, Chuang SY et al. (2008) Obesity pandemic, correlated factors and guidelines to define, screen and manage obesity in Taiwan. Obes Rev 9 , Suppl. 1, 22-31.

14. Hsiao YC \& Wka BM (2011) Prevalence of obesity and metabolic syndrome in aborigines in southeastern Taiwan: a hospital based study. J Intern Med Taiwan 22, 48-56.

15. Ko YC, Liu BH \& Hsieh SF (1994) Issues on aboriginal health in Taiwan. Gaoxiong Yi Xue Ke Xue Za Zbi 10, 337-351.

16. Pan WH, Chang HY, Yeh WT et al. (2001) Prevalence, awareness, treatment and control of hypertension in Taiwan: results of Nutrition and Health Survey in Taiwan (NAHSIT) 1993-1996. J Hum Hypertens 15, 793-798.

17. Lee MS, Wahlqvist ML, Yu HL et al. (2007) Hyperuricemia and metabolic syndrome in Taiwanese children. Asia Pac J Clin Nutr 16, Suppl. 2, 594-600.

18. Tu SH, Chen C, Hsieh YT et al. (2011) Design and sample characteristics of the 2005-2008 Nutrition and Health Survey in Taiwan. Asia Pac J Clin Nutr 20, 225-237.
19. Wu SJ, Chang YH, Wei IL et al. (2005) Intake levels and major food sources of energy and nutrients in the Taiwanese elderly. Asia Pac J Clin Nutr 14, 211-220.

20. Looker AC, Dallman PR, Carroll MD et al. (1997) Prevalence of iron deficiency in the United States. JAMA 277, 973-976.

21. World Health Organization (2001) Iron Deficiency Anaemia: Assessment, Prevention, and Control. Geneva: WHO.

22. Cook JD, Finch CA \& Smith NJ (1976) Evaluation of the iron status of a population. Blood 48, 449-455.

23. Wang JL \& Shaw NS (2005) Iron status of the Taiwanese elderly: the prevalence of iron deficiency and elevated iron stores. Asia Pac J Clin Nutr 14, 278-284.

24. Expert Panel on Detection, Evaluation, and Treatment of High Blood Cholesterol in Adults (2001) Exceutive summary of the Third Report of The National Cholesterol Education Program (NCEP) Expert Panel on Detection, Evaluation, and Treatment of High Blood Cholesterol in Adults (Adult Treatment Panel III). JAMA 285, 2486-2497.

25. Tan CE, Ma S, Wai D et al. (2004) Can we apply the National Cholesterol Education Program Adult Treatment Panel definition of the metabolic syndrome to Asians? Diabetes Care 27, 1182-1186.

26. World Health Organization (2000) The Asia-Pacific Persepective: Redefining Obesity and its Treatment. Geneva: WHO.

27. Chobanian AV, Bakris GL, Black HR et al. (2003) Seventh report of the Joint National Committee on Prevention, Detection, Evaluation, and Treatment of High Blood Pressure. Hypertension 42, 1206-1252.

28. Willett W \& Stampfer MJ (1986) Total energy intake: implications for epidemiologic analyses. Am J Epidemiol 124, $17-27$.

29. Barros AJ \& Hirakata VN (2003) Alternatives for logistic regression in cross-sectional studies: an empirical comparison of models that directly estimate the prevalence ratio. BMC Med Res Methodol 3, 21.

30. Lee J \& Chia KS (1993) Estimation of prevalence rate ratios for cross sectional data: an example in occupational epidemiology. Br J Ind Med 50, 861-862.

31. Salonen JT, Tuomainen TP, Nyyssonen K et al. (1998) Relation between iron stores and non-insulin dependent diabetes in men: case-control study. BMJ 317, 727 .

32. Ruddell RG, Hoang-Le D, Barwood JM et al. (2009) Ferritin functions as a proinflammatory cytokine via iron-independent protein kinase $\mathrm{C} \zeta$ /nuclear factor $\kappa \mathrm{B}$-regulated signaling in rat hepatic stellate cells. Hepatology 49, 887-900.

33. Acton RT, Barton JC, Passmore LV et al. (2006) Relationships of serum ferritin, transferrin saturation, and HFE mutations and self-reported diabetes in the Hemochromatosis and Iron Overload Screening (HEIRS) study. Diabetes Care 29, 2084-2089.

34. Zacharski LR, Ornstein DL, Woloshin S et al. (2000) Association of age, sex, and race with body iron stores in adults: analysis of NHANES III data. Am Heart J 140, 98-104. 